\title{
To Strengthen the Pupil's Reading Skills in Pitch and Rhythmic Accuracy
}

\author{
Mingyue Zhou ${ }^{1}$ \\ ${ }^{1}$ University of Adelaide, Adelaide, South Australia, Australia \\ Correspondence: Mingyue Zhou, University of Adelaide, Adelaide, South Australia, Australia.
}

Received: December 30, 2019

Accepted: January 13, 2020

Online Published: January 15, 2020

doi:10.20849/aes.v5i1.702

URL: https://doi.org/10.20849/aes.v5i1.702

\begin{abstract}
This paper expounds a process of music teaching and learning. It is a project and it contains project outline, practicum log and evaluation. The purpose of the project is to strengthen the pupil's reading skills in pitch and rhythmic accuracy. The duration of the project is four weeks. This article reflects a specific process and influence from student by studying piano. Also, it provides some practical suggestion and reflection to teacher.
\end{abstract}

Keywords: project, reading skill, pitch, rhythm, music lesson, piano, practicum log, evaluation

\section{Project}

\subsection{Overall Aim}

To Strengthen the Pupil's Reading Skills in Pitch and Rhythmic Accuracy.

\subsection{Student Background}

Individual piano lessons with a student from Torrens vile primary school.

Using music tree part 1(activities and lesson book) as teaching material.

\subsection{Content}

Landmarks (F, C and $\mathrm{G})$

Interval of a $2 \mathrm{nd}$, 3rd, 4 th and 5th.

Ties, upbeat, rest, sharp and flat.

Time signature

Note values

\subsection{Learning Outcome 1}

Recognize landmarks (bass F, middle $\mathrm{C}$ and treble $\mathrm{G}$ ) and intervals (2nd, 3rd, 4th and 5th) fluently.

Assessment Criteria:

1) Remember the landmark by writing (writing in stave) and playing (playing keyboard) notes.

2) Using Warm-ups (Music tree part1 page 57) to find and learn the upper and lower intervals base on landmarks.

3) Playing County Fair and Improvisation to recognize the interval of 2nd, 3rd, 4th and 5th.

\subsection{Learning Outcome 2}

Read the basic signal (time signature, ties, staccato, legato, sharp and flat) and count the rhythm (rest, crochet, semibreve, minim and dotted minim) correctly.

\section{Assessment Criteria:}

1) Using exercise (music tree part 1 Activities page 54), clap rhythms of one piece separately (bass part and treble part) and then playing together (left hand in bass $\mathrm{F}$ and right hand in middle $\mathrm{C}$ ).

2) Imitating the rhythm played by teacher at first (playing one bar $3 / 4$ or $4 / 4$ in landmark with minim, crochet, dotted minim, semibreve and rest), and then creating own rhythm and saying. 


\subsection{Learning Outcome 3}

Demonstrate a higher familiar degree of pitch and rhythm and playing the new piece which has same characteristics evenly.

Assessment Criteria

1) Say the name of pitches (CDEFGAB) and intervals (2nd, 3rd, 4th and 5th) from random flash cards.

2) Play the piece (Music tree part 1 page 55 "Grand Entrance") in time with correct pitches and rhythm.

\section{Practicum Log}

\section{$2.1 \log 1$ 13/9/19 Ella 1st}

At the beginning of this lesson, I asked Ella some questions as usual. For example, 'Have you finished your homework?' 'Did you practice at home?' and the answer was exactly what I suspected- no. I try to ask why, and then she said her mother didn't tell her homework, and the printer was broken, so she didn't know the homework. I think that is a blatant excuse because when I asked her to find the music that we learned last week, she can open the correct page quickly. Nevertheless, I just said, 'could you please check the homework on the computer next time?' She said, 'Ok' Then, I started on the project, which recognizes the landmarks (bass F, middle C, and treble G) and intervals (2nd, 3rd, 4th, and 5th). At first, I gave her a stave, and let her draw crochet in treble G, bass $F$, and middle $C$. She can find the treble $G$ easily, but bring the wrong positions for middle $\mathrm{C}$ and bass $\mathrm{F}$. Fortunately, she soon corrected herself after I reminded her, and I explained that the middle $\mathrm{C}$ is in the middle between treble clef and bass clef, the bass F should be in the fourth line in bass clef. More than that, I asked her to point these three landmarks in the piece of the Music Tree 1 Activities book, and she did very well. Afterward, we move to the keyboard from the desk. I let her find all of the G, F, and C on the keyboard. When I made sure she could see everything exactly, I asked her to show me the landmarks on the keyboard. She started bass A and said 'A B C D E ....' to find the landmarks. I think she has got it all figured out regardless it needs to spend a bit time, and then we started to play the music in Music Tree 1 music book. When she played the 'County Fair,' she only could play the front part about four or five bars difficulty. At that time, I used to 'formal' body-language for her and seemed slightly 'threatening,' which is crossed my hand in the back and just stood there looking at her without saying anything. Because I think she has already know the landmarks so she can finish this piece by herself, and she has the same problem for three weeks, but she didn't pretend to solve them. In a few moments, she frowned and started playing the random notes in the keyboard for expressed her depressed and impatient. I think she was waiting for me to tell her the letter, but I didn't, and I just kept silence. I waited a second and I asked her to find all the landmarks in this music for me then I said 'Ella, you already know all the landmarks in this music; you should practice more for playing the music evenly, right?' She hesitated said, 'yes.' Then we move to the next piece, which is 'warm-up.' I told her the interval is the relationship between two notes, and she said she already knows, and she can point out the 2nd and 3rd from the 'warm-up,' then I added some aural training about 2 nd and 3rd. She is brilliant, and she finished it quite good, especially in the 'improvisation,' she can play smoothly due to become more familiar with the $3 \mathrm{rd}$.

\subsection{Log 2 20/9/19 Ella 2nd}

Ella was very excited to tell me that she had practiced at home this week when she came into the class, and I said, 'that's great, keep going.' We review the landmarks and the interval of 2nd and 3rd then started on the 'sight-playing' to learn the 4th and 5th. At first, I asked her to find the treble G, and then go down a four. She can see the D note smoothly, but I noticed that she used the thumb to play the letter instead of the second finger, which is a bit unusual. I afraid she will mess when she played the 4th and 5th, so I corrected her 'could you try to use one finger corresponds to one key? It may feel more comfortable.' Afterward, I asked her to find the middle $\mathrm{C}$ and then goes up a five, so she can know the difference between the 4th and 5th. Also, she can play the exercise evenly by one hand, but when I let her play on both sides, it seemed difficult for her. Next, I move to the 'music math.' Ella can tell me the meaning of time signature clearly, but she was ambiguous in the mark of rests except for the crochet. I explained the difference between minim rest and semibreve rest for her, and I said 'you can imagine extra 'weight' in the semibreve rest compared with the minim rest, causing it to 'swing down' below the line.' Also, we review some primary signal, which is staccato, legato, sharp, and flat. And then we learn a new accidental, which is a natural mark. She handled it very fast. But when she played the D sharp in 'Cafeteria 1', I didn't tell her the sharp last for a whole bar, so the next D in the same bar needs to be sharpened as well. So she didn't notice this thing, which is my mistake. 


\section{$2.3 \log 3$ 18/10/19 Ella $3 r d$}

Ella had a long holiday for three weeks, and she even forgot to have a piano lesson today. So she came to the class without lesson books. I asked her, 'How are you? Did you practice your homework during the holiday?' She smiled and looks a little guilty then said, 'no, because I didn't have a chance to play the piano, there is not have a piano in my grandfather's home.' I asked her, 'so you didn't know your homework at all?' She hesitated to say 'yes.' I noticed that she always look at me and afraid that I would criticize her, so I just said 'Ok, it's all right, could you keep practice and bring your book next week?' Then we started on the rhythm exercise from Music Tree 1 activities book. She remembers the meaning of time signature, but she was a mess when I pointed the minim and asked her how many beats in this rhythm. So I told her which one is crochet, and then she think of the minim, dotted minim, semibreve, but still ambiguous in minim and semibreve rest.

We quickly review the basic rhythm then I asked her to walk the beat of the book. She was very brilliant. I just showed her a short example, and then she had finished the rest of the rhythms by herself. Next, we moved to the keyboard, and I used rhythms to do some aural training. At first, I played four-beat within a bar, which included crochet, minim, dotted minim, and rest. Then she can imitate what I had played quite well. Secondly, I asked her told me what rhythms I had played. She spent little to think about it because she cannot remember the name of rhythm clearly. Thirdly, I asked her to use these kinds of rhythms to play, and I will copy her. I played a bit wrong rhythms, sounds tricky, and asked her, 'Is that right?' Which make her smiled and said no. So she played again and told me what she has played. Fortunately, she handles it very well, and I think she had a better understanding and mastery of these primary rhythms. Afterward, we move to a sharp, flat, and natural. I asked her find the bass $f$ at first and then played F sharp. She said, 'sharp is going up, going the right way,' then she finds a correct note. I said, 'could you find a middle $\mathrm{C}$ and then played $\mathrm{C}$ flat?'

Because I think C flat is a special note, which played in the white key. What I foreseen happened, she played B flat. Then I explained 'no matter sharp or flat, we just move a semitone, so the flat is going down a semitone, which is from C to B, it is a special example.' She knows the natural played a white key, so we move to the next key point. I asked her to read the dominant sentence in the book 'sharp and flat last within a bar.' And then I asked her 'if there is an F sharp at the beginning of the bar, and then it has another F within the bar, the following F should be sharpened or not? 'She said, 'yes.' I said, 'if there is an F in the next bar, it should be sharpened or not?' She said, 'No.' so we started to play some music which included sharp, flat and natural. I think she has done these accidental quite well.

\subsection{Log4 25/10/19 Ella 4th}

I had ready to teach Ella, but she was absent, so she was not able to complete the final check that I hope to make for the project.

\section{Practicum Evaluation}

\subsection{Introduction}

The project aims to strengthen the pupil's reading skills in pitch and rhythmic accuracy. The biggest challenge in this project is how to enhance student's sight-reading ability and interest in music in the limited time. Sight-reading skill is one of the most important aspects of piano learning, which includes notes, rhythms, expressive marks, and lots of stuff at the same time. Improve student's sight-reading skills can help them practice more precise, more comfortable, and even independent. In this project, I have met some situations which are quite common in music teaching, and I have learned lots of practical approach to solve these circumstances.

\subsection{Background}

This project based on the situation that the pupil cannot practice independently. Ella is the pupil who has almost finished the Music Tree part 1, but she still cannot handle the musical knowledge of this book very well. The pupil seldom practices after class, and the excuse is that she cannot practice without her father's accompany. Because only her father knows whether she played it correctly or not. Thus, the pupil needs to learn to practice independently, and it may also motivate her interest in music. Because when learning piano ceases to be a complicated task by strengthening her reading skills, the pupil more likely to play the piano actively. The sight-reading skills of this project include the understanding of landmarks (middle $\mathrm{C}$, treble $\mathrm{G}$ and bass $\mathrm{F}$ ), some necessary intervals ( 2nd, 3rd, 4th and 5th), simple rhythms ( crochet, minim, dotted minim and semibreve), and some essential signals ( time signature, sharp, flat, natural, rest, staccato and legato). Ella has already learned these contents before, but the problem is how to use it expertly on the music. 


\subsection{Allocate Lesson Time and Content Reasonably}

First of all, for the pupil who does not practice after class, the most prominent challenge is how to achieve the well-balanced in lesson content and time. In the situation that a student does not practice homework at all, I prefer to review the homework in the class at the beginning. One of the reasons is for ensuring the pupils understand knowledge and know-how to practice; another reason is that it may deepen the impression of the critical point she had learned before by reviewing. But the lesson is for teaching instead of practicing. So how to distribute the lesson time is very important. I usually use ten minutes for the consolidation of ancient knowledge and spend twenty minutes to learn some new stuff within a thirty-minute class. More specifically, I will use ten minute to check the pupil whether understanding the homework or not, because some people do not practice caused by laziness, and some students may due to incapability. I tend to figure out what the problem is and solve them. The rest of twenty minute is for study new knowledge.

Nonetheless, Ella was a particular student who stops in the identical problem for three weeks because she never practices and helps her review the homework in the lesson need to spend too much time she was unwilling to consider the music and just waiting for my answers. So I adjusted the progress of the lesson. At first, I let her recognize the landmarks and intervals in the stave and keyboard separately (LO1, AC1.1). Then I connect the landmarks with the music when she can remember the landmarks clearly. Also, I let her to distinguished 2nd and 3rd of interval in 'warm-up' (LO1, AC1.2) by aural training and looking at the music. She can finish all this knowledge very well, especially when I asked her to play the 'improvisation' (LO1, AC1.3). She becomes more familiar with the 2nd and 3rd when I told her the conception of step and skip, so she has played the 'improvisation' evenly because of the music consist of 3rd. However, Ella was feeling stranger in 4th and 5th, which means that she is challenging to find the first note and relate a letter to its nearest landmark. Undoubtedly, it still requires much practicing after class.

\subsection{Try to Initiate Conversations and Less Explanation}

Secondly, the lesson needs more sufficient asking rather than telling. In the beginning, when the pupil cannot recognize the mark of rest quickly, I always explain immediately. Also, during the playing, I will point out the mistake for the student, such as which note or rhythm is a fault, and then give the correct answer. But I found this way is not very helpful for Ella, because she has quickly forgotten the knowledge I have told her before. For example, I told her the difference between minim rest and semibreve rest (LO2, AC2.1) when she cannot distinguish them, but she forgot in the next lesson. I realized that she is too lazy to think about the music, even when I explained the knowledge and answer to her, so I decided to do fewer things for Ella. We did some aural training of rhythms in the lesson (LO2, AC2.2). She can imitate what I just played, but she cannot respond to what exact rhythm it is. I played rhythms compose of crochet, crochet rest and minim, and I did not say the answer immediately, I just asked 'what do you think?' 'Which one sounds longer?' 'The first one, second or third?' and then she can gradually find the answer by herself. I become more active and try to initiative conversations instead of eliciting simple yes/no responses. Too much explanation and 'telling' in the lesson likely to make the lesson tedious and dull, especially for the student who is hard to concentrate.

\subsection{Be More Active and Less Passive}

Thirdly, a long 'silence' should be avoided in the lesson. I used to 'keep quiet' in the experience, which means I seldom speak loudly, communicate frequently, or do some exaggerated movement. In most cases, I am apt to ask Ella a question, and then I did not say anything and wait for her answer because I want her to think of the problem. But she usually 'keep silence' as well; which will make the lesson seems awkward. For instance, when she played the 'County Fair' (Music Tree 1), she cannot recognize the note $\mathrm{C}$ in the third space in treble clef, which is in a higher octave than middle C. So I asked, 'which note it is?', and she guesses wildly. 'A! No, B! No, G?' and eventually, she gave up, slouching in front of the piano with a depressive face. We did not have any interaction. After a while, we move to the next section. In the next time, once she met the problem again, she did not want to solve them anymore.

I realized that it was a passive circumstance, and I need to engage Ella more in the conversation to promote discussion and learning. In the teaching of sharp and flat marks, it has an emphasis should be paying more attention than 'sharp and flat last within a bar.' So when Ella noticed this crucial point in her playing and has a bit confused about that, I made some questions to ensure she reminded comfortable and started to think about it. Such as 'if it has an F sharp in the beginning, so the next F within a bar should be Sharpen or not?' 'if there still has an F in next bar, it needs to sharpen or play natural?' Generally, these kinds of questions can help Ella deeper understand the knowledge and use it masterly. So, make the student work is very important in teaching. 


\subsection{Conclusion}

In conclusion, I had ready to teach Ella in the fourth lesson, but she was absent, which means Ella was not able to complete the final test that I hope to make for the project. Therefore, it was hard to evaluate the result of this project formally. Overall, this project ultimately has $70 \%$ succeed. In terms of student, Ella has improved a lot in sight-reading skills. She had become more familiar with the landmarks, intervals, and some essential marks. But she still needs to practice more to relate the note to the nearest landmark, which may help her play the music quickly and smoothly. As for me, I have enhanced my teaching ability to conduct this project. I realized that the lesson requires most of the time to teach new knowledge instead of review the practice. Otherwise, it will diminish student's interest and motivation. Besides, I try to initiate sufficient asking rather than telling, and I become more persuasiveness to ensure that Ella comfortably reminded the knowledge. Besides, I change the mode of teaching from passive to active, which can make the student more concentration and consideration in the lesson. All the above aspects generate a significant impact on my teaching experience, and I will keep strengthening my vital and energetic approach in my teaching.

\section{Reference}

Clark, F., Goss, L., Clark, A., Goss, L., \& et al. (2002). The Music Tree Activities book Part 1. Alfred Publishing.

\section{Copyrights}

Copyright for this article is retained by the author(s), with first publication rights granted to the journal.

This is an open-access article distributed under the terms and conditions of the Creative Commons Attribution license (http://creativecommons.org/licenses/by/4.0/). 